\title{
Programming Adaptive Laboratory Evolution of 4- Hydroxyisoleucine Production Driven by a Lysine Biosensor in Corynebacterium Glutamicum
}

\section{Xinping Yu}

Jiangnan University

Feng Shi ( $\nabla$ shifeng@jiangnan.edu.cn )

Jiangnan University https://orcid.org/0000-0002-4345-506X

Haiyan Liu

Jiangnan University

Shuyu Tan

Jiangnan University

Yongfu Li

Jiangnan University

\section{Original article}

Keywords: 4-Hydroxyisoleucine, Corynebacterium glutamicum, Adaptive laboratory evolution, Programming evolution, LysG-PlysE, Lys biosensor

Posted Date: May 5th, 2021

DOI: https://doi.org/10.21203/rs.3.rs-463814/v1

License: (c) (1) This work is licensed under a Creative Commons Attribution 4.0 International License. Read Full License 


\section{Abstract}

4-Hydroxyisoleucine (4-HIL) is a promising drug for treating diabetes. In our previous study, 4-HIL was synthesized from self-produced L-isoleucine (Ile) in Corynebacterium glutamicum by expressing an Ile dioxygenase gene. Although the 4-HIL production of recombinant strain SZ06 increased significantly, a by-product, L-lysine (Lys) was accumulated because of the share of the first several enzymes in lle and Lys biosynthetic pathways. In this study, programming adaptive laboratory evolution (ALE) was designed and conducted in SZ06 to promote 4-HIL biosynthesis. At first, a programming evolutionary system pMK was constructed, which contains a Lys biosensor LysG-P $\mathrm{IySE}_{\mathrm{S}}$ and an evolutionary actuator composed of a mutagenesis gene and a fluorescent protein gene. The evolutionary strain SZ06/pMK was then let to be evolved programmatically and spontaneously by sensing Lys concentration. After successive rounds of evolution, nine mutant strains K1 - K9 with significantly increased 4-HIL production and growth performance were obtained. The maximum 4-HIL titer was $152.19 \pm 14.60 \mathrm{mM}, 28.4 \%$ higher than that in SZ06. This titer was higher than those of all the metabolic engineered $C$. glutamicum strains ever constructed. The whole genome sequencing of the nine evolved strains revealed approximately 30 genetic mutations in each strain. Only one mutation was directly related to the Lys biosynthetic pathway. Therefore, programming ALE driven by Lys biosensor can be used as an effective strategy to increase 4HIL production in C. glutamicum.

\section{Key Points}

- Lys-sensing evolution system was designed to drive programming ALE in glutamicum.

- Programming evolution based on Lys biosensor was applied to improve 4-HIL production.

- Positive mutants with higher 4-HIL titer were quickly obtained via programming ALE.

\section{Introduction}

According to the ninth edition of the Diabetes Atlas published by the International Diabetes Federation in 2019, more than 463 million adults are suffered from diabetes worldwide, and this number will reach 578.4 million by 2030 and up to 700.2 million by 2045 (Saeedi et al. 2019). Among these populations, the populations with type 2 diabetes mellitus (T2DM) accounts for approximately $90 \%$. These patients are characterized by various degrees of insulin deficiency and extensive insulin resistance. Encouragingly, ( $2 S, 3 R, 4 S)$-4-hydroxyisoleucine (4-HIL), which was found in fenugreek (Trigonella foenum-graecum) (Neelakantan et al. 2014), exhibits the particular glucose-dependent insulin-stimulating and insulinsensitizing activities. Thus, 4-HIL becomes a promising drug for treating the T2DM (Zafar and Gao 2016). Traditionally, 4-HIL is extracted from fenugreek seeds, but its yield is only $150 \mathrm{mg} / \mathrm{kg}$ (Jetté et al. 2009). Fortunately, the a-ketoglutarate ( $\mathrm{a}-\mathrm{KG}$ )-dependent L-isoleucine dioxygenase (IDO) derived from Bacillus thuringiensis was found to specifically convert L-isoleucine (Ile) to 4-HIL (Ogawa et al. 2011). 4-HIL was then synthesized by overexpressing the IDO gene (ido) in Escherichia coli, however, the addition of lle makes such process costly and inefficient (Smirnov et al. 2010). 
Corynebacterium glutamicum is globally recognized as safe and is widely used in the production of various amino acids (Becker et al. 2018; Tsuge and Matsuzawa 2021). In our previous study, through overexpressing ido gene derived from $B$. thuringiensis YBT-1520 in an lle-producing $C$. glutamicum ssp. lactofermentum strain SN01, $65.44 \pm 2.27 \mathrm{mM} 4$-HIL was synthesized from the self-produced lle (Shi et al. 2015). In order to improve 4-HIL production, metabolic engineering was performed, such as synergistically enhancing the substrates supply and IDO activity by particular gene overexpression and deletion (Shi et al. 2016; Shi et al. 2018; Shi et al. 2019). The engineered strain SZ06 could produce $111.99 \pm 2.15 \mathrm{mM} 4-\mathrm{HIL}$ (Shi et al. 2019). Although the 4-HIL production of SZ06 increased significantly, a by-product, L-lysine (Lys) was also accumulated, because the first several enzymes of the lle biosynthetic pathway are involved in Lys biosynthesis simultaneously. Furthermore, diaminopimelate, an intermediate metabolite of the Lys biosynthetic pathway, is required for cell growth, making it difficult to weaken the Lys biosynthesis. The accumulation of Lys limits the further increase of 4-HIL production.

Adaptive laboratory evolution (ALE) has become a powerful strategy in metabolic engineering. Compared with traditional metabolic design, ALE generates non-intuitive beneficial mutations that can occur in many different gene regions simultaneously under specific selection pressures (Portnoy et al. 2011). This natural selection provides an effective basis for obtaining new characteristics, phenotypes, and beneficial mutations in microorganisms, which can be fixed after multiple rounds of continuous evolution (Desai and Fisher 2007). It is precisely because of the rapid adaptation of microorganisms to different environments, the application of ALE for phenotypic optimization has been extended to various aspects, such as isolating the best strains, activating latent pathways, and improving environmental tolerance of production strains, etc (Portnoy et al. 2011; Sandberg et al. 2019). This phenotypic optimization not only improves overall cell function but also improves the physiological adaptation of microbial strain. Because normally, the adaptive rate under specific selection pressures is directly coupled to the growth rate, this coupled metabolic design will result in significantly higher production and lower by-products (Fong et al. 2005). For example, ALE was successfully applied to improve cellular tolerance of a $C$. glutamicum strain to high concentrations of methanol, thereby enhancing methanol biotransformation, meanwhile, the cell growth was also improved (Tuyishime et al. 2018; Wang et al. 2020). ALE was used to develop potential evolutionary strains of Zymomonas mobilis that can co-utilize glucose and xylose (Millán et al. 2020). Besides lowering effects by toxic chemicals, ALE has also been successfully used to improve production with C. glutamicum. For example, ALE combined with rare codon-rich markers was applied to select a mutant strain with 3.7-fold increased production of L-arginine (Arg) (Zheng et al. 2018). ALE combined with metabolic engineering was successfully used to improve the production of putrescine in C. glutamicum (Li et al. 2018). Through ALE driven by an L-valine (Val) biosensor Lrp- $P_{b r n F E}$ in combination with atmospheric and room temperature plasma mutagenesis, an mutant strain HL2-7 was successfully obtained and its Val production increased by $21.47 \%$ (Han et al. 2020).

However, when the selection pressure coupled to growth is not available, the desired mutant strains are difficult to be screened out by ALE. In addition, the mutation rate is too low when ALE is performed under natural evolution. Considering these two problems, ALE was ameliorated by using feed-back regulated 
evolution of phenotype (FREP) to increase the mutation rate and the population diversity (Binder et al. 2013). The FREP is actually a programming adaptive control system, in which the mutation rate is improved under the initial condition and decreased under the final condition when the concentration of target metabolites increased, thus resulting in higher positive screening rate (Chou and Keasling 2013). FREP is implemented in two parts: a biosensor for sensing the concentration of the target metabolite to generate the transcriptional signal and an actuator for changing the mutation rate when receives transcriptional signal. In this case, the sensor consists of two components: a transcription factor (TF) that binds to the target metabolite and a promoter that is regulated by the TF. The actuator is usually a mutagenesis gene, which can shorten the evolution time. The effect of FREP was successfully verified by evolving $E$. coli strains to increase the production of tyrosine and isoprenoid, meanwhile, a fluorescent protein, another actuator, was expressed in order to detect the visible changes in the evolved strains (Chou and Keasling 2013). Delightfully, more and more researches have been conducted in the field of TF-based biosensors. However, sensors that can be used for metabolic engineering of C. glutamicum is limited, for example, the branched-chain amino acids (BACCs) and L-methionine biosensor Lrp- $\mathrm{P}_{\text {brnFE }}$ (Mustafi et al. 2012; Tan et al. 2020), Lys, L-histidine (His), and Arg biosensor LysG-P/ysE $($ Schendzielorz et al. 2014; Kortmann et al. 2019), and shikimic acid biosensor ShiR-P shiA (Liu et al. 2017).

lysE encodes the Lys, His, and Arg export protein, while LysG, an LysR-Type TF, is a positive regulator of lysE transcription. In the presence of intracellular Lys, Lys binds to LysG, leading LysG to bind in the promoter region of $l y s E$, thereby promoting the transcription of $l y s E$ (Bellmann et al. 2001). Recently, an optical Lys sensor pSenLys was constructed based on LysG-P ${ }_{\text {lysE, }}$ and several new Lys producer were generated by fluorescence-activated cell sorting (FACS) of mutant strains harboring this sensor (Binder et al. 2013). Subsequently, semi-conserved LysG was designed to construct the biosensor pSenHis with focused His and Arg specificity and the His-producing mutant strains of $C$. glutamicum was obtained through this pSenHis-based FACS (Della Corte et al. 2020).

In this study, in order to improve the 4-HIL production and reduce the by-product Lys production, a programming ALE driven by the Lys-sensing evolution system was employed. Firstly, a Lys-sensing evolution system pMK was constructed. It containes two parts: the Lys biosensor LysG-P/ysE and the actuator composed of a mutagenesis gene $c d d$ and a fluorescent reporter gene egfp. cdd gene encodes the cytosine deaminase. It has been used in genome editing to cause specific mutations at target sites and generate gene silencing (Banno et al. 2018; Wang et al. 2019). cdd was used here to accelerate mutation and evolution. Thereby, the mutation rate and eGFP fluorescence intensity of cells may be positively regulated in this system according to the intracellular Lys concentration. Secondly, the evolutionary strain SZ06/pMK was constructed and programming ALE was conducted to generate the evolved positive mutants. Finally, the whole genome of these mutant strains was sequenced and the mutations in these evolved strains were analyzed.

\section{Materials And Methods}




\section{Strains, plasmids, and culture conditions}

The strains and plasmids used in this study are listed in Table 1. E. coil JM109 was used for gene cloning and propagation. E. coil cells were grown in Luria-Bertani (LB) medium at $37^{\circ} \mathrm{C}$ and $200 \mathrm{rpm}$. C. glutamicum ssp. lactofermentum SZ06 was used as the initial strain for 4-HIL production. C. glutamicum was cultivated in LBB medium ( $5 \mathrm{~g} / \mathrm{L}$ trypone, $2.5 \mathrm{~g} / \mathrm{L}$ yeast extract, $5 \mathrm{~g} / \mathrm{L} \mathrm{NaCl}$, and $18.5 \mathrm{~g} / \mathrm{L}$ brain heart infusion powder) at $30^{\circ} \mathrm{C}$ and $200 \mathrm{rpm}$. If necessary, $30 \mu \mathrm{g} / \mathrm{mL}$ kanamycin and $10 \mu \mathrm{g} / \mathrm{mL}$ chloramphenicol was added to the media to promote plasmid maintenance.

Table 1

Bacterial strains and plasmids used in this study

\begin{tabular}{|c|c|c|}
\hline $\begin{array}{l}\text { Strains or } \\
\text { plasmids }\end{array}$ & Description & Source \\
\hline \multicolumn{3}{|l|}{ Strains } \\
\hline JM109 & plasmid propagating strain of $E$. coli & Novagen \\
\hline SZ06 & Ile-producing strain of C. glutamicum ssp. lactofermentum & $\begin{array}{l}\text { Shi et al. } \\
2019\end{array}$ \\
\hline SZ06/pMK & SZ06 harboring pMK & This work \\
\hline MKn & positively evolved mutant strains of SZ06/pMK & This work \\
\hline $\mathrm{Kn}$ & final evolved strains of MKn that lose pMK & This work \\
\hline \multicolumn{3}{|l|}{ Plasmids } \\
\hline pJYW-4 & constitutive expression vector of $C$. glutamicum, $\mathrm{Km}^{\mathrm{R}}$ & $\begin{array}{l}\text { Hu et al. } \\
2014\end{array}$ \\
\hline pDTW109 & $\begin{array}{l}\text { creexpressing vector of } C \text {. glutamicum, temperature-sensitive, } \\
\mathrm{Cm}^{\mathrm{R}}\end{array}$ & $\begin{array}{l}\text { Hu et al. } \\
2013\end{array}$ \\
\hline pMK & $\begin{array}{l}\text { pDTW109 harboring lysG and } \mathrm{P}_{\text {lysE }} \text { controlled cdd-egfp genes, } \\
\mathrm{Cm}^{\mathrm{R}}\end{array}$ & This work \\
\hline
\end{tabular}

\section{Construction of evolution plasmid and C. glutamicum strain for ALE}

A Lys-sensing evolution plasmid containing Lys biosensor lysG-P $\mathrm{P}_{\text {lys }}$ and evolution actuator cdd-egfp was constructed as follow. The primers used in this study are listed in Table 2. The lysG-P/ysE fragment and cdd gene were amplified from the genome of strain SN01. Then they were fused with chemically synthesized egfp gene by overlap PCR. Next, the PCR product lysG-P ${ }_{l y s E}$ cdd-egfp was digested with Sall and Pstl and ligated into the Sall- and Pst-digested plasmid pDTW109, generating the Lys-driven evolution plasmid pMK. Finally, the pMK was transformed into C. glutamicum SZ06, generating the evolutionary strain SZ06/pMK. 
Table 2

Primers used in this study

\begin{tabular}{|c|c|c|}
\hline Primers & Sequence $\left(5^{\prime}-3^{\prime}\right)$ & $\begin{array}{l}\text { Restriction } \\
\text { sites }\end{array}$ \\
\hline IysG-P ${ }_{\text {lysE }}-\mathrm{R}$ & TAATGTCGACTTAAGGCCGCAATCCCTCG & Sall \\
\hline lysG-P ${ }_{\text {lysE }}-\mathrm{F}$ & АССАTССТАTAАСTССТTCTCGGTCCGATGGACAGCAAAAG & \\
\hline egfp-F & AGAAGGAGTTATAGGATGGTTTCCAAGGGCG & \\
\hline egfp-R & TTACTTGTACAGCTCGTCC & \\
\hline$c d d-\mathrm{F}$ & AGTAAGAGAGGAGGGATTGCATGACTGAAGATGACTTAGATCTG & \\
\hline$c d d-\mathrm{R}$ & AGTACTGCAGCTAAAGAGCCTTATCCGGAG & Pst \\
\hline 16s-RNA-1 & ACCTGGAGAAGAAGCACCG & \\
\hline 16s-RNA-2 & TCAAGTTATGCCCGTATCG & \\
\hline dapC-1 & TCTTATGTGGGGGCTACACC & \\
\hline $\operatorname{dap} C-2$ & CATCACGATCCCCAATATCC & \\
\hline $\begin{array}{l}\text { CGB98_RS08395- } \\
1\end{array}$ & GGTCCTAACGCTTTCGACTG & \\
\hline $\begin{array}{l}\text { CGB98_RS08395- } \\
2\end{array}$ & GCTGTTCAGTGCGTGGATAA & \\
\hline $\begin{array}{l}\text { CGB98_RS10415- } \\
1\end{array}$ & TGTCAATAACTCGCCTGGTG & \\
\hline $\begin{array}{l}\text { CGB98_RS10415- } \\
2\end{array}$ & CAGTGCATCAACGTGGACTT & \\
\hline actA-1 & TGCAACCTCСTTCTССTTGT & \\
\hline actA-2 & TGCCATAGATGTCAGCTTCG & \\
\hline $\begin{array}{l}\text { CGB98_RS10920- } \\
1\end{array}$ & TGCACGTAAAGACGGAGTTG & \\
\hline $\begin{array}{l}\text { CGB98_RS10920- } \\
2\end{array}$ & GTTGCCGTAGATGTCGTTGA & \\
\hline Restriction sites are & ndicated in boldface & \\
\hline
\end{tabular}

\section{Adaptive laboratory evolution}

The evolutionary strain SZ06/pMK was precultured in the seed medium for $18 \mathrm{~h}$, inoculated into fermentation medium as described previously (Shi et al. 2019), and then cultured and evolved spontaneously for $48 \mathrm{~h}$ at $30^{\circ} \mathrm{C}, 200 \mathrm{rpm}$. Subsequently, $4 \%$ volume of cultured broth was transferred into fresh fermentation medium to proceed a new round of evolution under the same conditions (Fig. 1a). 
During evolution, $1 \mathrm{~mL}$ broth was harvested every $12 \mathrm{~h}$ to detect eGFP fluorescence intensity. The evolution process was ceased and the evolved cells were harvested when the relative fluorescence intensity no longer reduced. After dilution, the cells were spread onto LBB plates and incubated at $30^{\circ} \mathrm{C}$ for $36 \mathrm{~h}$, then 22 single colonies were picked randomly for purification. Next, they were pre-cultured and then cultured in 24 deep-well plate with $2 \mathrm{~mL}$ medium in each well. The amino acid concentration was detected as described below to select the positively evolved strains MKn. Finally, the MKn were cultivated at $37^{\circ} \mathrm{C}$ for $24 \mathrm{~h}$ to cure pMK and to obtain pMK-free strains $\mathrm{Kn}$.

\section{Fluorescence assays}

The fermentation broth of SZ06/pMK was diluted by $1 \mathrm{M}$ hydrochloric acid and then transferred into a black 96-deep-well plate with clear bottom (Corning-Costar plates) for detection. Before each test, the plate was vibrated in Cytation 5 (BiotTek) for $30 \mathrm{~ms}$. The biomass was detected at $562 \mathrm{~nm}$ and the eGFP fluorescence was determined at an excitation wavelength of $479 / 20 \mathrm{~nm}$ and an emission wavelength of $520 / 20 \mathrm{~nm}$. When characterizing the sensor, Lys was added into the well to a final concentration of 0,5 , 10,20 , and $30 \mathrm{mM}$, and fluorescence was measured as above after incubating the plate in the Cytation5 for certain time.

\section{4-HIL Fermentation}

For 4-HIL fermentation in a shake flask, cells were precultured, inoculated into optimized fermentation medium and then cultured as described previously (Shi et al. 2019). One $\mathrm{mL}$ of fermentation broth was harvested every $24 \mathrm{~h}$ to measure the cell density, $\mathrm{pH}$, residual glucose, and amino acids and 4-HIL concentrations by the methods described previously (Shi et al. 2018). The conversion ratio of lle to 4-HIL was calculated as the mole of 4-HIL divided by the total moles of Ile and 4-HIL. The amino acids and 4HIL concentrations were detected by HPLC analysis by the method described previously (Shi et al. 2016).

\section{Genome sequencing and analysis of genetic mutations}

The genome of mutant strains was sequenced using an Illumina HiSeq 4000 system (San Diego, CA, USA) at the Beijing Genomics Institute (Shenzhen, China) and compared with the reference genome of $C$. glutamicum WM001 (NCBI: GCF_002220135.1). Genomic DNA was sheared randomly to construct nine read libraries with lengths of 240 bp by a Bioruptor ultrasonicator (Diagenode, Denville, NJ, USA) and physicochemical methods. The paired-end fragment libraries were sequenced according to the lllumina HiSeq 4000 system's protocol after the low abundant sequences were filtered. Raw reads of low quality from paired-end sequencing were discarded.These quenched reads were assembled using SOAP de novo v1.05 software. Each query sequence was then aligned with the reference sequence using the alignment softwares MUMmer (http://mummer.sourceforge.net/) and LASTZ

(http://www.bx.psu.edu/miller_lab/dist/README.lastz-1.02.00/) to get the alignment results (Kurtz et al. 2004; Harris 2007). The variation sites between the query sequence and reference sequence were found out and filtered preliminarily to detect single nucleotide polymorphisms (SNP) and insertion-deletion (InDel) sites.

\section{RT-PCR analysis of genes' transcription}


Real-time PCR (RT-PCR) was used to analyze transcription levels of target genes of mutant strains during fermentation. The samples collected at the mid-exponential phase were used for RT-PCR experiments and the methods are performed as described previously (Chen et al. 2015; Wang et al. 2015). The relative abundance of mRNA of target genes was quantified by measuring the cycle threshold (Ct) value and calculating the $2^{-\Delta \Delta C t}$ value. Primers for RT-PCR are summarized in Table 2.

\section{Results}

\section{Characterization of Lys biosensor LysG-P lysE}

The natural LysG-P $P_{\text {lysE }}$ biosensor was applied in several studies to monitor the cellular production of Lys, Arg, and His and to screen their better producer (Binder et al. 2012; Schendzielorz et al. 2014; Eggeling and Bott 2015). In our designed programming evolution system here, the natural LysG-P/ysE was used as the Lys biosensor. When Lys concentration is high, the Lys biosensor will be activated, thereby activating the expression of $c d d$ and egfp and increasing the mutation rate and the eGFP fluorescence intensity of cells (Fig. 1b). When Lys concentration is lower, the Lys biosensor will not be activated, thereby weakening the expression of $c d d$ and egfp and decreasing the mutation rate and the relative eGFP fluorescence intensity. Before performing the programming ALE, the sensitivity and response range of the

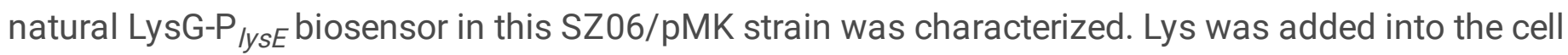
suspension of SZ06/pMK until 5, 10, 20, and $30 \mathrm{mM}$. The relative eGFP fluorescence intensity increased significantly as the Lys concentration increased from $5 \mathrm{mM}$ to $30 \mathrm{mM}$ (Fig. 2), suggesting the positive correlation between the expression level of LysG-P ${ }_{\text {IySE }}$ biosensor-controlled egfp and the Lys concentration in the range of $5-30 \mathrm{mM}$. A previous research also verified that $30-40 \mathrm{mM}$ Lys was sufficient to induce the expression of lysE (Bellmann et al. 2001). The response of the biosensor to Lys ranged from 1.09- to 1.37-fold. Therefore, this evolution system can respond to the varied Lys concentration and can then be applied for programming ALE.

\section{Programming adaptive laboratory evolution of SZ06/pMK}

The strain SZ06/pMK evolved continuously for several rounds (Fig. 1a). At each round, the relative eGFP fluorescence intensity was measured to judge the destination of evolution. The relative eGFP fluorescence intensity decreased continuously during evolving within each round (Fig. 1c), whereas the final fluorescence of each round increased slightly in the first several rounds of evolution and dropped significantly at the seventh round (Fig. 1d). Meanwhile, the final biomass of each round decreased slightly in the first several rounds and increased at the seventh and eighth rounds. After eight rounds, the final fluorescence intensity dropped to 5370 and nearly did not decrease. Thereby, the evolution was ceased and the evolved individual strains were separated on plate. After separation, 22 single colonies were randomly selected and the 4-HIL production of these mutants were detected. 21 mutants showed significantly higher 4-HIL titer $(43.31-63.98 \mathrm{mM})$ than the initial strain SZ06 $(36.90 \mathrm{mM})$, thereby the positive mutation rate reached $95.5 \%$ (Fig. 3a). The 4-HIL titer of 4 mutant strains, i.e. MK1, MK2, MK3, 
and MK4 increased to more than $160.0 \%$ of that of SZ06 (Fig. 3b). However, the Lys titer (11.44-15.77 $\mathrm{mM}$ ) did not reduce significantly as compared to $\mathrm{SZ06}(9.29 \mathrm{mM})$.

Some studies have utilized ALE to force strains to adapt to alternative growth environments, thus accelerating the growth rate of cells and obtaining mutants with significantly improved performance (Lee et al. 2010; Tuyishime et al. 2018; Wang et al. 2020). The shortest evolution period of most ALE was 15 days (Stella et al. 2019), comparable with 8 rounds evolution here. Considering the accelerated and programming evolution in our pMK system, we attempted to shorten the evolution time of programming ALE and to test if we can obtain desired positive mutant strains more quickly.

The programming evolution of strain SZ06/pMK was performed again as previously for only three rounds. 22 mutant strains were randomly screened and their 4-HIL production was determined. 12 mutant strains produced more 4-HIL $(54.93-79.67 \mathrm{mM})$ than SZ06 $(44.99 \mathrm{mM})$, and the positive mutation rate reached $54.5 \%$ (Fig. 3a). The 4-HIL titer of 5 mutants, i.e. MK5, MK6, MK7, MK8, and MK9, was 72.41 $79.67 \mathrm{mM}$, more than $160.0 \%$ of that of SZ06 (Fig. 3b). The Lys titer $(6.75-16.52 \mathrm{mM})$ did not decrease obviously as compared to SZ06 $(5.98 \mathrm{mM})$. These results demonstrates that the Lys-sensing evolution system can control the programming evolution by sensing Lys concentration. Meanwhile, positive mutants with higher 4-HIL production can be obtained in much shorter evolution time.

\section{4-HIL production of envolved mutants}

The 4-HIL production of the nine mutants MK1 - MK9 was then evaluated in shake flask. In consistent with the result obtained in 24 deep-well plate, all the nine mutant strains showed higher 4-HIL titer than the control strain SZ06; meanwhile, they exhibited similar growth curves and glucose consumption curve (Fig. 4). The final biomass and glucose consumption of MK1 - MK4 were a little higher than that of SZ06 (Fig. 4a), while those of MK5 - MK9 were nearly same as SZ06 (Fig. 4b).

After $144 \mathrm{~h}$ fermentation, 4-HIL production of MK1 - MK4 increased to 104.82 - $146.29 \mathrm{mM}$ (Fig. 4c), while that of MK5 - MK9 increased to $92.72-102.31 \mathrm{mM}$ (Fig. 4d). Although 1.33-18.85 mM lle was remained in MK1 - MK9 after fermented in 24-well plates, nearly no lle was remained after fermented in shake flasks and the conversion ratio of lle to 4-HIL was almost close to $100.0 \%$. Among these 9 mutants, the maximum 4-HIL titer was $146.30 \pm 25.47 \mathrm{mM}$, which was $89.5 \%$ higher than the control strain SZ06 $(78.44 \pm 12.08 \mathrm{mM})$. However, the concentration of by-product Lys of these 9 mutants $(21.14-33.70 \mathrm{mM})$ increased as compared to SZ06 (18.93 $\pm 1.74 \mathrm{mM})$ (Fig. 4c and 4d).

To obtain the genetically stable strains after programming ALE, the pMK plasmid was cured in MK1 MK9. The final evolved strains K1 - K9 were then fermented in shake flasks. The growth and glucose consumption curves of all the final evolved strains were similar to those of SZ06 (Fig. 5a and 5b). Meanwhile, the final biomass of $\mathrm{K} 1, \mathrm{~K} 3$, and $\mathrm{K} 6$ was nearly $5.0 \%$ higher than that of SZ06, and all glucose was exhausted at $72 \mathrm{~h}$ by $\mathrm{K} 1-\mathrm{K} 9$.

Furthermore, K1 - K9 accumulated 128.87-152.19 mM 4-HIL, which was 10.6-28.4\% higher than SZ06 $(118.56 \pm 7.21 \mathrm{mM})$ (Fig. 5c and 5d). Particularly, K3 produced most 4-HIL (152.19 $\pm 14.60 \mathrm{mM})$ among 
the eight rounds-evolved $\mathrm{K} 1$ - K4 strains, while among the three rounds-evolved $\mathrm{K} 5$ - $\mathrm{K} 9$ strains, $\mathrm{K} 9$ produced most 4-HIL $(146.05 \pm 15.48 \mathrm{mM}), 28.4 \%$ and $23.2 \%$ higher than that of SZ06, respectively. Similarly, the concentration of by-product Lys of K1 - K9 $(23.98-31.42 \mathrm{mM})$ increased slightly. Recently, the optimal dynamic control strain ST17 and RBS fine-tuning strain SF12 accumulated $135.34 \pm 12.55$ $\mathrm{mM}$ and 139.82 $\pm 1.56 \mathrm{mM} 4$-HIL, respectively in shake flask (Shi et al. 2020; Tan et al. 2020). SF12 was nearly the highest titer so far. Pleasurably, the 4-HIL production of K3 was $8.1 \%$ higher than that of SF12. The result demonstrates that the programming ALE driven by Lys biosensor can successfully generate $C$. glutamicum mutant strains with higher 4-HIL production.

\section{Genetic mutations of the evolved strains}

Finally, the whole-genome sequencing of $\mathrm{K} 1$ - $\mathrm{K} 9$ strains was conducted in order to identify mutations in their genome. An average of 32 mutations were revealed in each strain. The common mutation sites of these 9 strains contained 3 SNPs and $6 \mathrm{InDel}$, among them, 4 mutations were located in the coding regions, i.e. CGB98_RS02465, CGB98_RS09630, and CGB98_RS12800 encoding a 16S ribosomal RNA, a $\mathrm{HNH}$ endonuclease (endonuclease Dnase I/II), and IS6 family transposase, respectively (Table 3 ). The $16 \mathrm{~S}$ ribosomal RNA is involved in the protein translation. It also affects the stem-loop structure of mRNA, thus affecting gene expression and growth performance of cells. The IS6 family transposase allows genes to change position. However, the influence of these mutation could not be verified, because of the mutiple copies of these genes in the genome. 
Table 3

Mutations discovered in evolved strains $\mathrm{K} 1-\mathrm{K} 9$

\begin{tabular}{|c|c|c|c|c|}
\hline $\begin{array}{l}\text { Genome } \\
\text { position }\end{array}$ & Gene/IGR & Annotation/Product & Mutation & $\begin{array}{l}\text { Variant } \\
\text { ratio }\end{array}$ \\
\hline Del514815A & CGB98_RS02465 & $16 \mathrm{~S}$ ribosomal RNA & Del461A & $8 / 9$ \\
\hline T2052533C & CGB98_RS09630 & HNH endonuclease & T291C & $9 / 9$ \\
\hline \multirow{2}{*}{$\begin{array}{l}\text { Del2720013A } \\
\text { Del2720032T }\end{array}$} & \multirow[t]{2}{*}{ CGB98_RS12800 } & \multirow[t]{2}{*}{ IS6 family transposase } & Del105T & \multirow[t]{2}{*}{$7 / 9$} \\
\hline & & & Del86A & \\
\hline In519737T & $\begin{array}{l}\text { CGB98_RS02475- } \\
02480\end{array}$ & $\begin{array}{l}5 S \text { ribosomal RNA copy B (rrf) and } \\
\text { putative succinyl diaminopimelate } \\
\text { transaminase }(\text { dapC }) \text {, respectively }\end{array}$ & $\begin{array}{l}\text { In- } 111 \mathrm{~T} \\
\text { of dapC }\end{array}$ & $8 / 9$ \\
\hline A1791301G & $\begin{array}{l}\text { CGB98_RS08395- } \\
08400\end{array}$ & $\begin{array}{l}\text { peptidoglycan endopeptidase and } \\
\text { cytochrome bc complex cytochrome b } \\
\text { subunit, respectively }\end{array}$ & $\begin{array}{l}\text { T-476C } \\
\text { of } \\
\text { RS08395 }\end{array}$ & $4 / 9$ \\
\hline Del2206093A & $\begin{array}{l}\text { CGB98_RS10415- } \\
10420\end{array}$ & $\begin{array}{l}\text { ABC transporter ATP-binding protein } \\
\text { and } 5 \mathrm{~S} \text { ribosomal RNA }(r r f) \text {, respectively }\end{array}$ & $\begin{array}{l}\text { Del-235T } \\
\text { of } \\
\text { RS10415 }\end{array}$ & $9 / 9$ \\
\hline T2231742G & $\begin{array}{l}\text { CGB98_RS10555- } \\
10560\end{array}$ & $\begin{array}{l}\text { tRNA-Lys and succinate CoA } \\
\text { transferase (act } A) \text {, respectively }\end{array}$ & $\begin{array}{l}\mathrm{A}+20 \mathrm{C} \\
\text { of } \operatorname{act} A\end{array}$ & $4 / 9$ \\
\hline Del2309538T & $\begin{array}{l}\text { CGB98_RS10915- } \\
10920\end{array}$ & $\begin{array}{l}\text { hypothetical protein and FAD-binding } \\
\text { protein, respectively }\end{array}$ & $\begin{array}{l}\text { Del }+ \\
\text { 159A of } \\
\text { RS10920 }\end{array}$ & $9 / 9$ \\
\hline
\end{tabular}

The other common mutations occurred in the intergenic region. These mutations may affect the expression of their downstream genes, i.e. dapC, CGB98_RS08395, and CGB98_RS10415, or their adjacent upstream genes, i.e. actA and CGB98_RS10920 (Table 3). Therefore, the transcription level of these genes in highest producer, i. e. K3 and K9 was verified by RT-PCR. Among these genes, only dapC are related to Lys biosynthetic pathway, while CGB98_RS08395 may promote cell wall degradation and affect the synthesis of peptidoglycan.

dapC encodes the $\mathrm{N}$-succinyl-aminoketopimelate aminotransferase (DapC). It is dispensable for the synthesis of $d$, I-diaminopimelate via the succinylase branch. Other research demonstrated that overexpression of dapC resulted in a 9-fold increase in this specific aminotransferase activity, along with an increase in Lys production (Hartmann et al. 2003). In K3 and K9, the relative transcription level of dapC increased significantly to 16.78- and 36.54-fold, respectively at $24 \mathrm{~h}$ as compared with SZ06 at $24 \mathrm{~h}$ (Fig. 6a), while after $48 \mathrm{~h}$, their relative transcription level increased slightly to 2.96 - and 1.43-fold of SZ06 (Fig. 6b). This might reslut in somewhat higher Lys accumulation in K3 and K9. In addition, the biomass of most mutant strains was a little higher than that of SZ06. The increased transcription level of the dapC gene might also affect the peptidoglycan synthesis and cell growth. CGB98_RS08395 encodes a peptidoglycan endopeptidases, proteins that are essential for promoting cell wall degradation and viability of bacterial cells (Shin et al. 2020). In K3, the transcription level of this gene significantly 
increased to 39.14 -fold and 4.63 -fold at $24 \mathrm{~h}$ and $48 \mathrm{~h}$, respectively as compared with SZ06, in consistent with a higher biomass of $\mathrm{K} 3$.

CGB98_RS10415 encodes the ATP-binding protein of an ABC transporter. ABC transporters mainly mediate the absorption of essential nutrients into cells and the transport of molecules out of cells or into organelles, powered by ATP hydrolysis (Beis 2015). In K9, its transcription level at $24 \mathrm{~h}$ increased significantly to 28.93 -fold as compared with SZ06, while in K3, its transcription level also increased to 2.13-fold. Both $\mathrm{K} 3$ and $\mathrm{K} 9$ strains performed a better growth, suggesting that this gene can promote the cell growth to some extent. actA encodes succinate CoA transferase which can supply succinyl CoA, an intermediate of TCA cycle and a precursor of Lys biosynthetic pathway. In K9, the transcription level of this gene significantly promoted to 5.97-fold and 2.18-fold as compared with SZ06 at $24 \mathrm{~h}$ and $48 \mathrm{~h}$, respectively, thereby may increase the metabolic pool of TCA cycle and promote the running of TCA cycle, thus improving the 4-HIL production of mutant strains. Meanwhile, in the biosynthetic pathway of Lys, DapC converts a succinylated intermediate and succinyl CoA is required as the substrate by DapD for synthesizing this succinylated intermediate. The promoted expression of actA and supply of succinyl CoA may also enhance the Lys biosynthesis, thereby increasing the Lys accumulation in K9. CGB98_RS10920 encodes a FAD-binding protein. In $\mathrm{K} 9$, the relative transcription level of this gene rised to 8.36-fold and 5.76 -fold of that SZ06 at $24 \mathrm{~h}$ and $48 \mathrm{~h}$, respectively. While in $\mathrm{K} 3$, its transcriptional level decreased greatly at $24 \mathrm{~h}$ and increased significantly at $48 \mathrm{~h}$. In conclusion, this programming ALE generated a total of 290 mutations in 9 evolved strains, and most of these mutations are independent of the 4-HIL biosynthetic pathway, thereby may be the non-intuitive mutations. Only $d a p C$ is related directly to Lys biosynthetic pathway, while act $A$ is involved in the synthesis of succinyl CoA and thereby influences Lys biosynthesis. The upregulation of $d a p C$ and actA in these evolved strains would result in the accumulation of Lys. The increased expression of CGB98_RS08395 may affect cell survival and the sysnthesis of peptidoglycan.

\section{Discussion}

ALE is a powerful strategy in metabolic engineering to significantly improve growth performance and phenotypes of strains. Some studies have utilized ALE to force strains to adapt to alternative growth environments and to obtain mutants with significantly improved performance. For example, a $C$. glutamicum strain with improved tolerance to high concentrations of methanol was successfully obtained by ALE, thereby enhancing methanol biotransformation, meanwhile, the cell growth was also improved (Tuyishime et al. 2018; Wang et al. 2020). ALE was successfully applied for improving the tolerance of $E$. coli to sabinene, and the sabinene production was increased to 8.43-fold (Wu et al. 2020). ALE was also applied for generating a $C$. glutamicum strain with higher growth rates on glucose minimal medium (Pfeifer et al. 2017). But the mutation rate is too low when ALE is performed under natural evolution, thereby much long time is required for running such ALE cycle. It usually takes several months, such as in the case that $C$. glutamicum ATCC 13032 was adapted on glucose minimum medium for more than 1500 generations, i.e. approximately 7 months, and finally several faster growing mutants were isolated (Wang et al. 2018). The shortest time for ALE is about two weeks, for example, C. glutamicum 
strains with improved utilization of D-xylose were obtained by using miniaturized and automated ALE within 13 days (Radek et al. 2017). Furthermore, if the selection pressure coupled to growth is not available, the desired mutant strains are difficult to be screened out by ALE. Thus, high-throughput screening, such as FACS, is usually designed for a specific phenotype, because the target metabolites can be visualized and the high-production strains can be obtained after extensive screening. The LysG- $\mathrm{P}_{\text {/ysE }}$ or

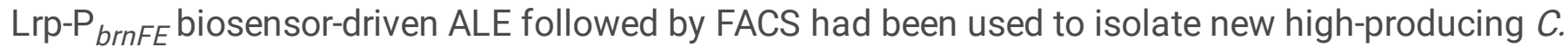
glutamicum mutants (Binder et al. 2012; Mahr et al. 2015). However, FACS requires a large number of screenings to obtain the desired phenotype, and the application of FACS is limited by equipment and instrument.

In order to improve the mutation rate and reduce the screening effort, here, a Lys-sensing evolution system was constructed to accelerate and programme ALE process, and to further realize the controllability of the mutation rate. In the actuator, the mutagenesis gene $c d d$ under the control of LysG$\mathrm{P}_{\text {lysE }}$ biosensor was used to accelerate mutation and evolution, and the eGFP fluorescence intensity of cells was detected to monitor the evolutionary progress according to the intracellular Lys concentration. After eight rounds of evolution, the positive mutation rate based on 4-HIL titer reached $95.5 \%$, while after three rounds of evolution, it reached $54.5 \%$. Meanwhile, the later positive mutants produced a little more 4-HIL (54.93- $79.67 \mathrm{mM})$ as compared with the former positive mutants $(43.31-63.98 \mathrm{mM})$. The biomass and glucose consumption of all the nine best mutant strains $\mathrm{K} 1$ - K9 were nearly same as SZ06, among them, the growth performance of $\mathrm{K} 3$ and $\mathrm{K} 9$ was slightly better. $\mathrm{K} 1-\mathrm{K} 9$ accumulated $128.87-$ $152.19 \mathrm{mM}$ 4-HIL in shake flask, all higher than SZ06 (118.56 $\pm 7.21 \mathrm{mM})$. Among them, K3 reached the highest 4-HIL titer of $152.19 \pm 14.60 \mathrm{mM}$ and this is the highest titer reported so far. Compared to eight rounds of evolution, three rounds can also achieve mutant strains with higher 4-HIL production in a shorter evolution time. Regrettably, the Lys accumulation did not significantly reduce by this programming ALE, although the relative eGFP fluorescence intensity at the eighth round of evolution decreased. Such inconsistency may be partially due to the increased biomass after eight rounds of evolution (Fig. 1d). The difficulty for reducing Lys content is probably because that the Lys biosynthetic pathway is important for cell growth and peptidoglycan synthesis (Wehrmann et al. 1998; Hutton et al. 2007; Hochheim et al. 2017). The increased expression of $d a p C$ and act $A$ in our final evolved strains also verified the essential of Lys biosynthesis. In addition, some non-intuitive mutations generated by this programming ALE occurred in ribosomal genes, such as $16 \mathrm{~S}$ or $5 \mathrm{~S}$ ribosomal RNA genes. The mutations in these genes might accelerate the overall translation process of cells and thus improve their metabolic ability to synthesize 4-HIL and Lys.

In addition, programming ALE can cause numerous mutations as compared to natural evolution. Natural evolution produces nondirectional mutations that require more effort to screen and identify relevant targets, but there are only a few meaningful mutations. Recently, a metabolic engineering to guide evolution (MGE) was applied to improve Val producing strains by creating the evolutionary pressure and to get more beneficial mutations (Schwentner et al. 2018). In our study here, the programming ALE generated a total of 290 mutations in 9 evolved strains, and these mutations were almost unrelated to the 
4-HIL biosynthetic pathway. However, a mutant strain with significantly increased 4-HIL titer, i.e. K3 was finally obtained. These results verify the idea that programming ALE driven by the Lys-sensing evolutionary system can increase the mutation rate, shorten the evolution time, and generate mutant strains with better phenotype. Although the LysG-P $\mathrm{P}_{\text {ysE }}$ biosensor cannot be accurately characterized in

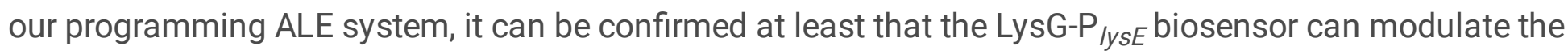
expression of its downstream gene(s) to a certain extent under different Lys levels, as proven by a research that Lys acted as an inducer to mediate the transcriptional activation ability of LysG, thereby controlling the expression of the downstream gene lysE (Bellmann et al. 2001).

A research that improved 4-HIL titer by seven steps of static metabolic engineering combined with one step of dynamic control finally generated a recombinant $C$. glutamicum strain YI (Zhang et al. 2018). Their modification contained codon optimization, gene deletion, promoter substitution, gene overexpression, dynamic modulation of emzyme activity, and so on, and it took long time to finish all modification and to obtain the final recombinant strain. In contrary, the Lys-sensing evolution system pMK can be constructed quickly within only 2 days, while the evolved strain K1 - K9 can be obtained within $20-30$ days. This design successfully achieved the highest 4-HIL producer at the shake flask level. The use of the programming ALE driven by Lys-biosensor opens new perspectives for the development of C. glutamicum strains with higher 4-HIL production. The programming ALE will be more powerful than the traditional evolution or metabolic engineering in the future. Regretly, the concentration of by-product Lys

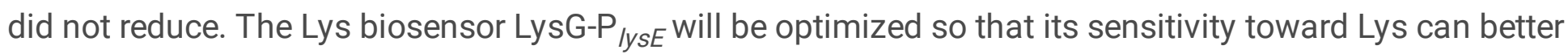
adapt the 4-HIL fermentation environment and drive the programming ALE to reduce the Lys content. Meanwhile, other strain with less Lys accumulation can be selected as the initial evolutionary strain.

\section{Abbreviations}

ALE: adaptive laboratory evolution; Arg: L-arginine; BACCs: branched-chain amino acids; Ct: cycle threshold; FACS: fluorescence-activated cell sorting; FREP: feed-back regulated evolution of phenotype; 4HIL: 4-hydroxyisoleucine; His: L-histidine; IDO: L-isoleucine dioxygenase; lle: L-isoleucine; InDel: insertiondeletion; a-KG: a-ketoglutarate; LB: Luria-Bertani; Lys: L-lysine; RT-PCR: Real-time PCR; SNP: single nucleotide polymorphisms; T2DM: type 2 diabetes mellitus; TF: transcription factor; Val: L-valine.

\section{Declarations}

Ethics approval and consent to participate This article does not contain any studies with human participants or animals performed by any of the authors.

Consent for publication Not applicable.

Availability of data and materials All data are included in the manuscript.

Competing interests The authors declare that they have no competing interests. 
Funding This work was supported by the program of State Key Laboratory of Food Science and Technology (SKLF-ZZA-201904).

Author's contributions FS conceived and designed research. XY, HL, and ST conducted experiments. FS and $X Y$ analyzed data. $F S, X Y$, and $Y L$ wrote the manuscript. All authors read and approved the manuscript.

Authors' information ${ }^{1}$ State Key Laboratory of Food Science and Technology, Jiangnan University, Wuxi 214122 , China. ${ }^{2}$ Key Laboratory of Industrial Biotechnology, Ministry of Education, School of Biotechnology, Jiangnan University, Wuxi 214122 , China. ${ }^{3}$ International Joint Laboratory on Food Safety, Jiangnan University, Wuxi 214122, China. ${ }^{4}$ National Engineering Laboratory for Cereal Fermentation Technology, Jiangnan University, Wuxi 214122, China.

Acknowledgments The authors thank the "program of State Key Laboratory of Food Science and Technology" (contract no. SKLF-ZZA-201904) for financial support.

\section{References}

1. Banno S, Nishida K, Arazoe T, Mitsunobu H, Kondo A (2018) Deaminase-mediated multiplex genome editing in Escherichia coli. Nat Microbiol 3(4):423-429. https://doi.org/10.1038/s41564-017-0102-6

2. Barrick JE, Yu DS, Yoon SH, Jeong H, Oh TK, Schneider D, Lenski RE, Kim JF (2009) Genome evolution and adaptation in a long-term experiment with Escherichia coli. Nature 461(7268):12431247. https://doi: $10.1038 /$ nature08480

3. Binder S, Schendzielorz G, Stäbler N, Krumbach K, Hoffmann K, Bott M, Eggeling L (2012) A highthroughput approach to identify genomic variants of bacterial metabolite producers at the single-cell level. Genome Biol 13(5):R40. https://doi: 10.1186/gb-2012-13-5-r40

4. Binder S, Siedler S, Marienhagen J, Bott M, Eggeling L (2013) Recombineering in Corynebacterium glutamicum combined with optical nanosensors: a general strategy for fast producer strain generation. Nucleic Acids Res 41(12):6360-6369. https://doi: 10.1093/nar/gkt312

5. Becker J, Rohles CM, Wittmann C (2018) Metabolically engineered Corynebacterium glutamicum for bio-based production of chemicals, fuels, materials, and healthcare products. Metab Eng 50:122141. https://doi: 10.1016/j.ymben.2018.07.008

6. Chen C, Li Y, Hu J, Dong X, Wang X (2015) Metabolic engineering of Corynebacterium glutamicum ATCC13869 for L-valine production. Metab Eng 29:66-75. https://doi: 10.1016/j.ymben.2015.03.004

7. Chou HH, Keasling JD (2013) Programming adaptive control to evolve increased metabolite production. Nat Commun 4:2595. https://doi: 10.1038/ncomms3595

8. Eggeling L, Bott M (2015) A giant market and a powerful metabolism: L-Lysine provided by Corynebacterium glutamicum. Appl Microbiol Biotechnol 99(8):3387-3394. https://doi:

$10.1007 /$ s00253-015-6508-2 
9. Harris RS (2007) Improved pairwise alignment of genomic DNA. Ph.D. Thesis, The Pennsylvania State University.

10. Hartmann M, Tauch A, Eggeling L, Bathe B, Möckel B, Pühler A, Kalinowski J (2003) Identification and characterization of the last two unknown genes, $d a p C$ and $d a p F$, in the succinylase branch of the Llysine biosynthesis of Corynebacterium glutamicum. J Biotechnol 104(1-3):199-211. https://doi: 10.1016/s0168-1656(03)00156-1

11. Han G, Xu N, Sun X, Chen J, Chen C, Wang Q (2020) Improvement of L-valine production by atmospheric and room temperature plasma mutagenesis and high-throughput screening in Corynebacterium glutamicum. ACS Omega 5(10):4751-4758. https://doi:

10.1021/acsomega.9b02747

12. Hochheim J, Kranz A, Krumbach K, Sokolowsky S, Eggeling L, Noack S, Bocola M, Bott M, Marienhagen J (2017) Mutations in MurE, the essential UDP-N-acetylmuramoylalanyl-D-glutamate 2,6-diaminopimelate ligase of Corynebacterium glutamicum: effect on L-lysine formation and analysis of systemic consequences. Biotechnol Lett 39(2):283-288. https://doi: 10.1007/s10529016-2243-8

13. Hu J, Li Y, Zhang H, Tan Y, Wang X (2014) Construction of a novel expression system for use in Corynebacterium glutamicum. Plasmid 75:18-26. https://doi.org/10.1016/j.plasmid.2014.07.005

14. Hu J, Tan Y, Li Y, Hu X, Xu D, Wang X (2013) Construction and application of an efficient multiplegene-deletion system in Corynebacterium glutamicum. Plasmid 70(3):303-313.

https://doi.org/10.1016/j.plasmid.2013.07.001

15. Hutton CA, Perugini MA, Gerrard JA (2007) Inhibition of lysine biosynthesis: an evolving antibiotic strategy. Mol Biosyst 3(7):458-465. https://doi: 10.1039/b705624a

16. Jetté L, Harvey L, Eugeni K, Levens N (2009) 4-Hydroxyisoleucine: a plant-derived treatment for metabolic syndrome. Curr Opin Investig Drugs 10(4):353-358

17. Kortmann M, Mack C, Baumgart M, Bott M (2019) Pyruvate carboxylase variants enabling improved Lysine production from glucose identified by biosensor-based high-throughput fluorescenceactivated cell sorting screening. ACS Synth Biol 8(2):274-281. https://doi: 10.1021/acssynbio.8b00510

18. Kurtz S, Phillippy A, Delcher AL, Smoot M, Shumway M, Antonescu C, Salzberg SL (2004) Versatile and open software for comparing large genomes. Genome Biol 5(2):R12. https://doi: 10.1186/gb2004-5-2-r12

19. Lee DH, Palsson $B \emptyset$ (2010) Adaptive evolution of Escherichia coli K-12 MG1655 during growth on a Nonnative carbon source, L-1,2-propanediol. Appl Environ Microbiol 76(13):4158-4168. https://doi: 10.1128/AEM.00373-10

20. Liu C, Zhang B, Liu YM, Yang KQ, Liu SJ (2017) New intracellular shikimic acid biosensor for monitoring shikimate synthesis in Corynebacterium glutamicum. ACS Synth Biol 7(2):591-601. https://doi: 10.1021/acssynbio.7b00339. 
21. Li Z, Shen YP, Jiang XL, Feng LS, Liu JZ (2018) Metabolic evolution and a comparative omics analysis of Corynebacterium glutamicum for putrescine production. J Ind Microbiol Biotechnol 45(2):123-139. https://doi: 10.1007/s10295-018-2003-y

22. Mahr R, Gätgens C, Gätgens J, Polen T, Kalinowski J, Frunzke J (2015) Biosensor-driven adaptive laboratory evolution of L-valine production in Corynebacterium glutamicum. Metab Eng 32:184-194. https://doi: 10.1016/j.ymben.2015.09.017

23. Millán C, Peña C, Flores C, Espín G, Galindo E, Castillo T (2020) Improving glucose and xylose assimilation in Azotobacter vinelandii by adaptive laboratory evolution. World J Microbiol Biotechnol 36(3):46. https://doi.org/10.1007/s11274-020-02822-5

24. Neelakantan N, Narayanan M, de Souza RJ, van Dam RM (2014) Effect of fenugreek (Trigonella foenum-graecum L.) intake on glycemia: a meta-analysis of clinical trials. Nutr J 13:7. https://doi.org/10.1186/1475-2891-13-7

25. Ogawa J, Kodera T, Smirnov SV, Hibi M, Samsonova NN, Koyama R, Yamanaka H, Mano J, Kawashima T, Yokozeki K, Shimizu S (2011) A novel L-isoleucine metabolism in Bacillus thuringiensis generating $(2 S, 3 R, 4 S)$-4-hydroxyisoleucine, a potential insulinotropic and anti-obesity amino acid. Appl Microbiol Biotechnol 89:1929-1938. https://doi: 10.1007/s00253-010-2983-7

26. Pfeifer E, Gätgens C, Polen T, Frunzke J (2017) Adaptive laboratory evolution of Corynebacterium glutamicum towards higher growth rates on glucose minimal medium. Sci Rep 7(1):16780. https://doi: 10.1038/s41598-017-17014-9

27. Radek A, Tenhaef N, Müller MF, Brüsseler C, Wiechert W, Marienhagen J, Polen T, Noack S (2017) Miniaturized and automated adaptive laboratory evolution: Evolving Corynebacterium glutamicum towards an improved d-xylose utilization. Bioresour Technol 245(Pt B):1377-1385. https://doi: 10.1016/j.biortech.2017.05.055

28. Saeedi P, Petersohn I, Salpea P, Malanda B, Karuranga S, Unwin N, Colagiuri S, Guariguata L, Motala AA, Ogurtsova K, Shaw JE, Bright D, Williams R; IDF Diabetes Atlas Committee (2019) Global and regional diabetes prevalence estimates for 2019 and projections for 2030 and 2045: results from the International Diabetes Federation Diabetes Atlas, 9th edition. Diabetes Res Clin Pract 157:10784. https://doi: 10.1016/j.diabres.2019.107843

29. Schendzielorz G, Dippong M, Grünberger A, Kohlheyer D, Yoshida A, Binder S, Nishiyama C, Nishiyama M, Bott M, Eggeling L (2014) Taking control over control: use of product sensing in single cells to remove flux control at key enzymes in biosynthesis pathways. ACS Synth Biol 3(1):21-29. https://doi: 10.1021/sb400059y

30. Schwentner A, Feith A, Münch E, Busche T, Rückert C, Kalinowski J, Takors R, Blombach B (2018) Metabolic engineering to guide evolution-Creating a novel mode for L-valine production with Corynebacterium glutamicum. Metab Eng 47:31-41. https://doi: 10.1016/j.ymben.2018.02.015

31. Shin JH, Sulpizio AG, Kelley A, Alvarez L, Murphy SG, Fan L, Cava F, Mao Y, Saper MA, Dörr T (2020) Structural basis of peptidoglycan endopeptidase regulation. Proc Natl Acad Sci USA 117(21):1169211702. https://doi: 10.1073/pnas.2001661117 
32. Tan S, Shi F, Liu H, Yu X, Wei S, Fan Z, Li Y (2020) Dynamic control of 4-hydroxyisoleucine biosynthesis by modified L-isoleucine biosensor in recombinant Corynebacterium glutamicum. ACS Synth Biol 9(9):2378-2389. https://doi: 10.1021/acssynbio.0c00127

33. Wang N, Ni Y, and Shi F (2015) Deletion of odhA or pyc improves $Y$-aminobutyric acid and its precursor L-glutamate production in recombinant Corynebacterium glutamicum. Biotechnol Lett 37(7):1473-1481. https://doi: 10.1007/s10529-015-1822-4

34. Wang Y, Liu Y, Li J, Yang Y, Ni X, Cheng H, Huang T, Guo Y, Ma H, Zheng P, Wang M, Sun J, Ma Y (2019) Expanding targeting scope, editing window, and base transition capability of base editing in Corynebacterium glutamicum. Biotechnol Bioeng 116(11):3016-3029. https://doi: $10.1002 /$ bit. 27121

35. Wang Z, Liu J, Chen L, Zeng AP, Solem C, Jensen PR (2018) Alterations in the transcription factors GntR1 and RamA enhance the growth and central metabolism of Corynebacterium glutamicum. Metab Eng 48:1-12. https://doi: 10.1016/j.ymben.2018.05.004

36. Wehrmann A, Phillipp B, Sahm H, Eggeling L (1998) Different modes of diaminopimelate synthesis and their role in cell wall integrity: a study with Corynebacterium glutamicum. J Bacteriol 180(12):3159-3165. https://doi: 10.1128/JB.180.12.3159-3165.1998

37. Wu T, Liu J, Li M, Zhang G, Liu L, Li X, Men X, Xian M, Zhang H (2020) Improvement of sabinene tolerance of Escherichia coli using adaptive laboratory evolution and omics technologies. Biotechnol Biofuels 13:79. https://doi: 10.1186/s13068-020-01715-x

38. Zafar MI, Gao F (2016) 4-Hydroxyisoleucine: a potential new treatment for type 2 diabetes mellitus. BioDrugs 30(4):255-262. https://doi.org/10.1007/s40259-016-0177-2

39. Zhang C, Li Y, Ma J, Liu Y, He J, Li Y, Zhu F, Meng J, Zhan J, Li Z, Zhao L, Ma Q, Fan X, Xu Q, Xie X, Chen $N$ (2018) High production of 4-hydroxyisoleucine in Corynebacterium glutamicum by multistep metabolic engineering. Metab Eng 49:287-298. https://doi: 10.1016/j.ymben.2018.09.008

40. Zheng B, Ma X, Wang N, Ding T, Guo L, Zhang X, Yang Y, Li C, Huo YX (2018) Utilization of rare codon-rich markers for screening amino acid overproducers. Nat Commun 9(1):3616. https://doi: $10.1038 / \mathrm{s} 41467-018-05830-0$

\section{Figures}


a

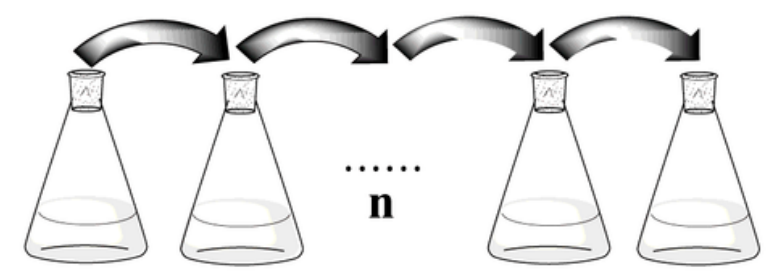

$n=3$ or 8

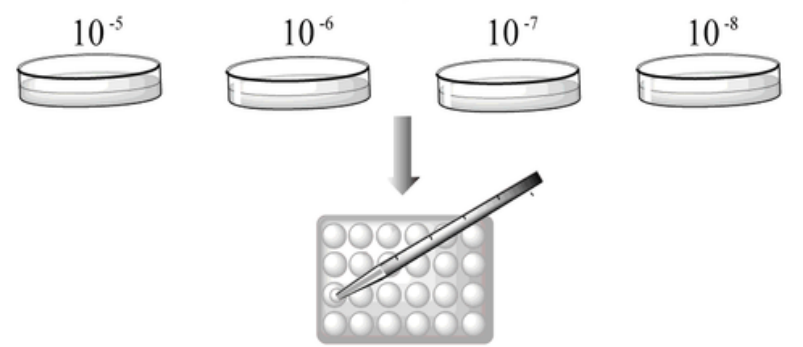

c

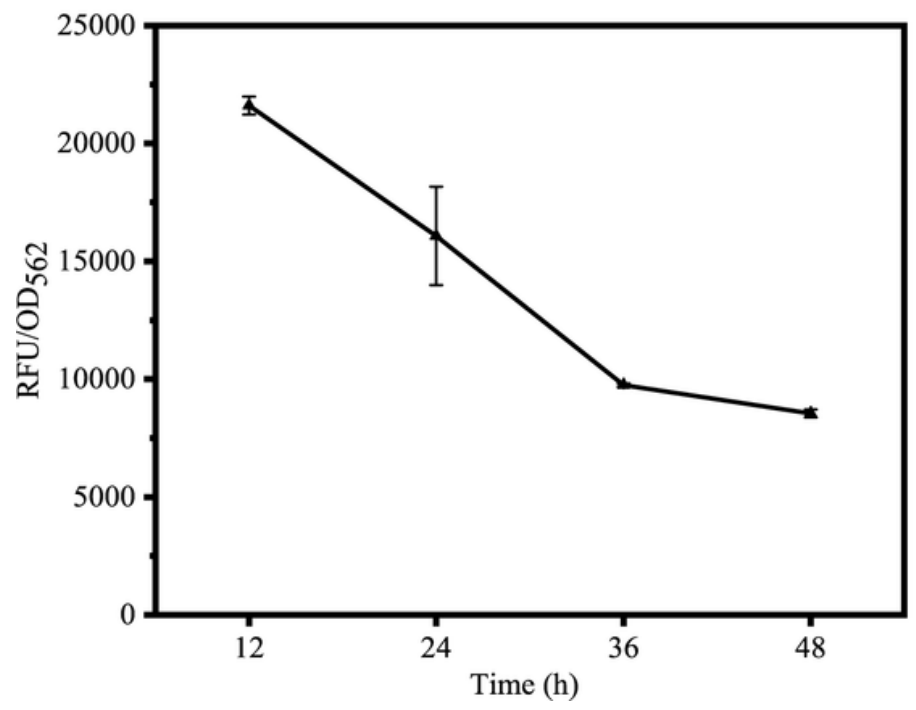

b

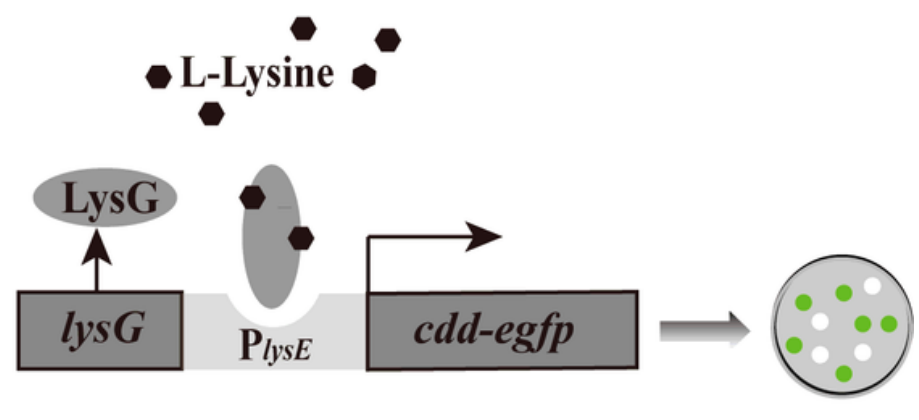

\section{lys $G$}

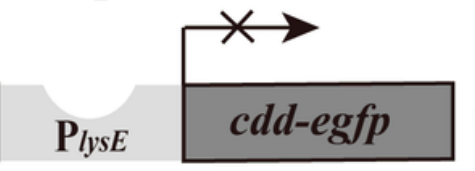

d

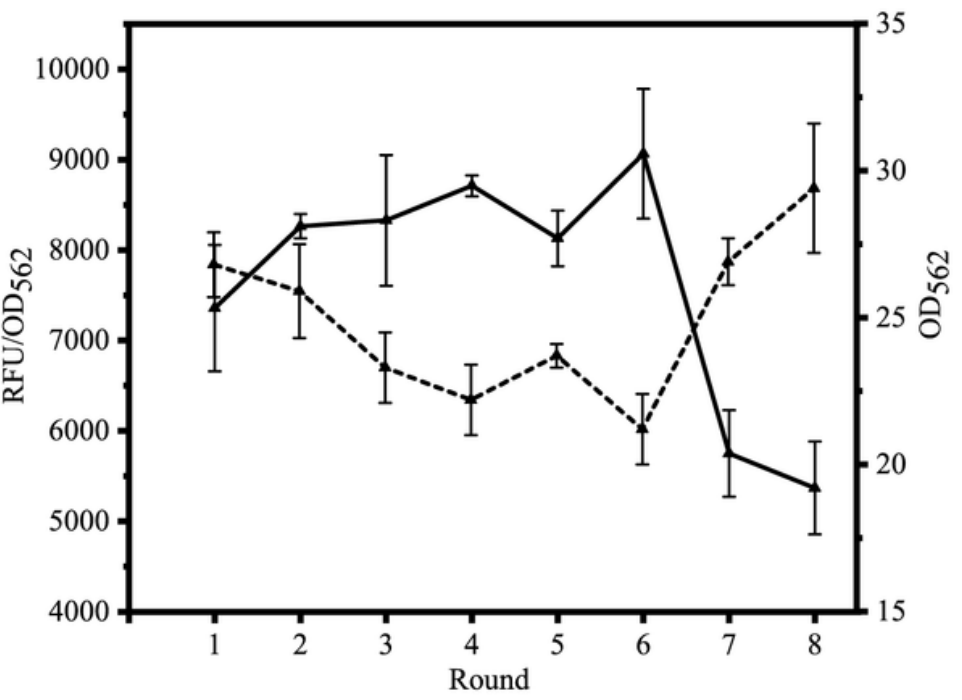

Figure 1

The Lys-biosensor based programming ALE process. The Lys biosensor senses the intracellular Lys concentration and regulates the expression level of the evolution actuator, thereby controls and indicates the evolution process. a Schematic of programming ALE process. The evolutionary strain SZ06/pMK was repeatedly and continuously cultured for several rounds in the same medium, the evolution process was ceased and the evolved cells were harvested when the relative eGFP fluorescence intensity no longer reduced significantly. Then, 22 single colonies were picked randomly for purification, and they were cultured in 24 deep-well plate. b The work diagram of pMK. When Lys concentration is higher, the biosensor was activated, thereby activating the expression of cdd and egfp and increasing the mutation rate and the eGFP fluorescence intensity of cells. When Lys concentration is lower, the Lys biosensor will not be activated, the relative eGFP fluorescence intensity will be decreased and the evolution process was ceased. c The change of relative eGFP fluorescence intensity in the 3rd round. $d$ The relative eGFP fluorescence intensity (solid line) and biomass (dotted line) of SZ06/pMK at $48 \mathrm{~h}$ of each round. 


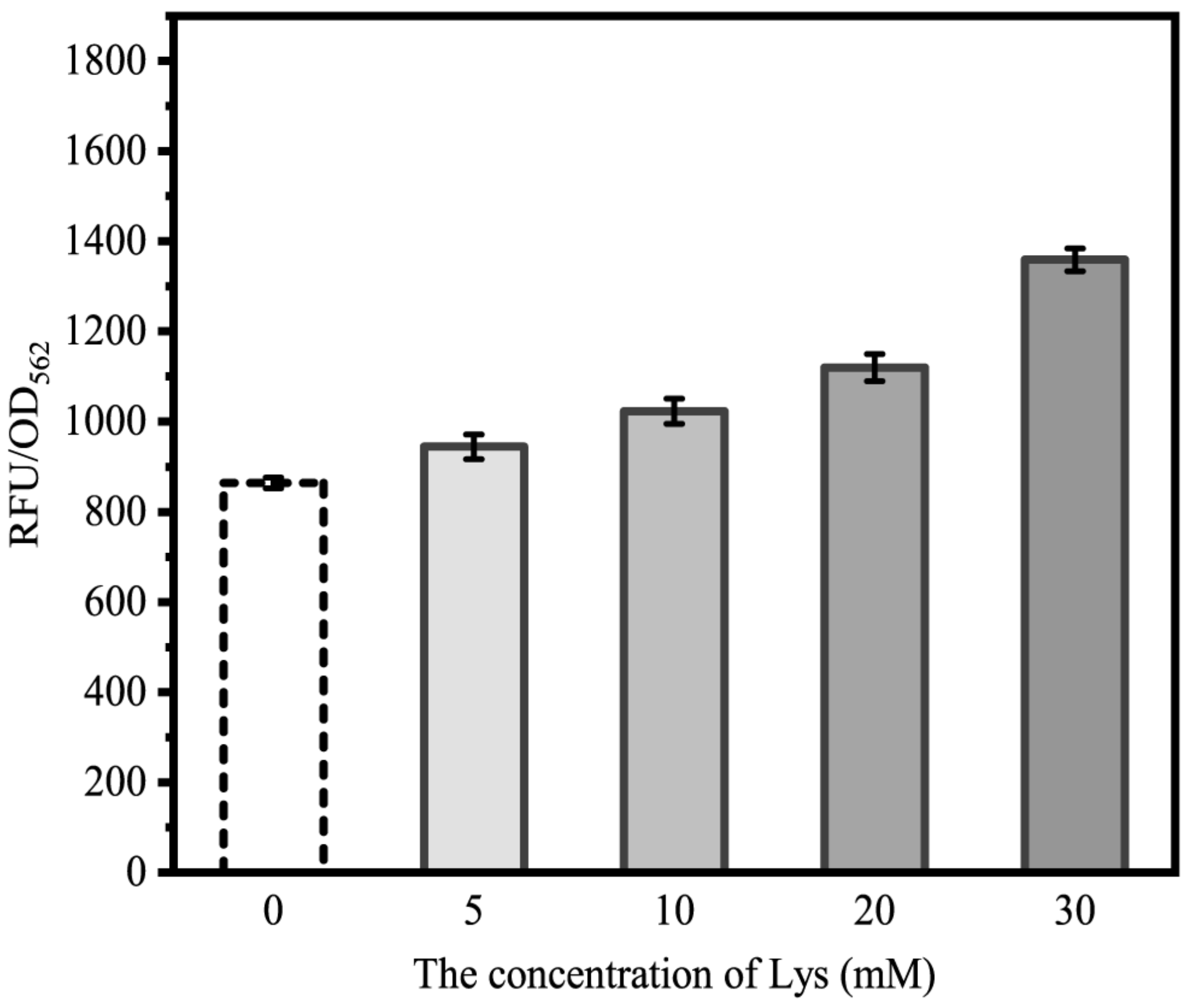

Figure 2

The response of the native LysG-PlysE biosensor in pMK to Lys. The relative eGFP fluorescence intensity of evolutionary strain SZ06/pMK was detected under different concentrations of Lys. 

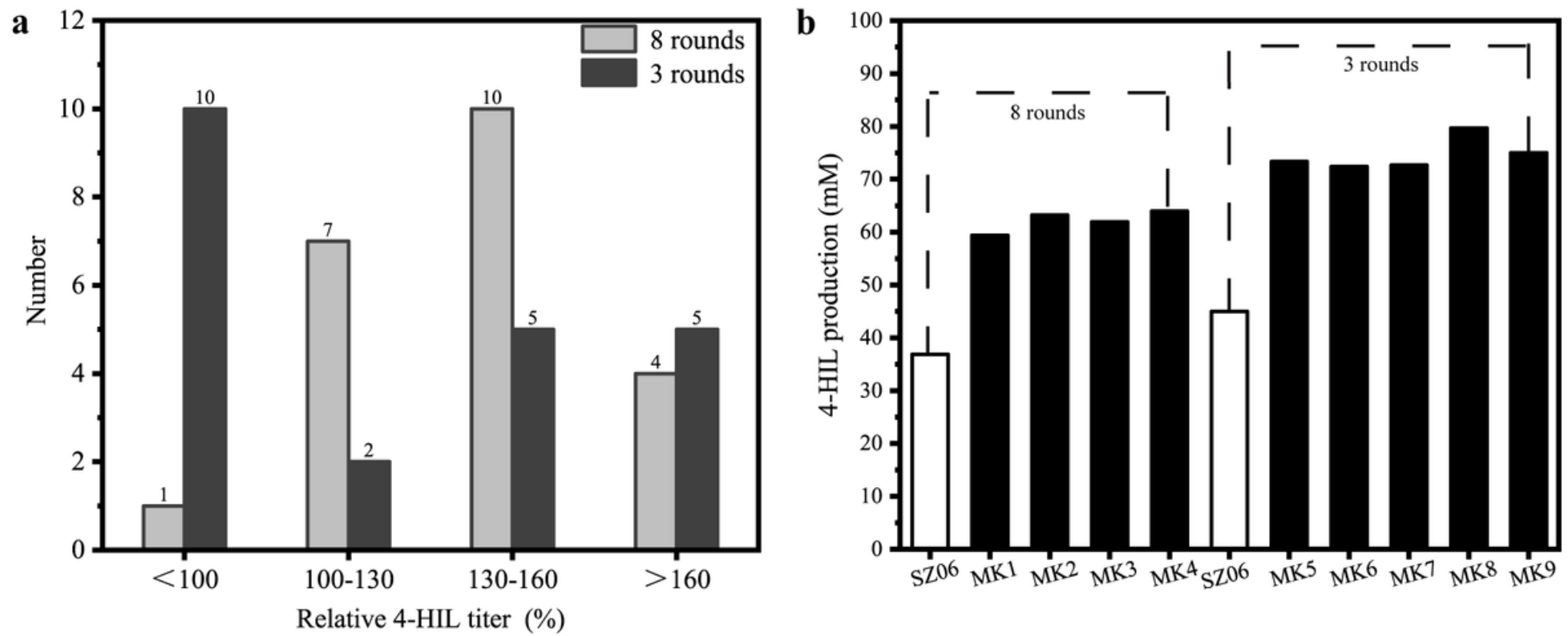

Figure 3

The 4-HIL production of preliminary screening strains in 24 deep-well plates after fermented for $96 \mathrm{~h}$. SZ06 was used as the control strain. a The distribution of relative 4-HIL production of mutant strains obtained by eight rounds or three rounds' evolution. $b$ mutant strains with a relative titer higher than $160 \%$, MK1-MK4 from the eighth round and MK5-MK9 from the third round, respectively. 

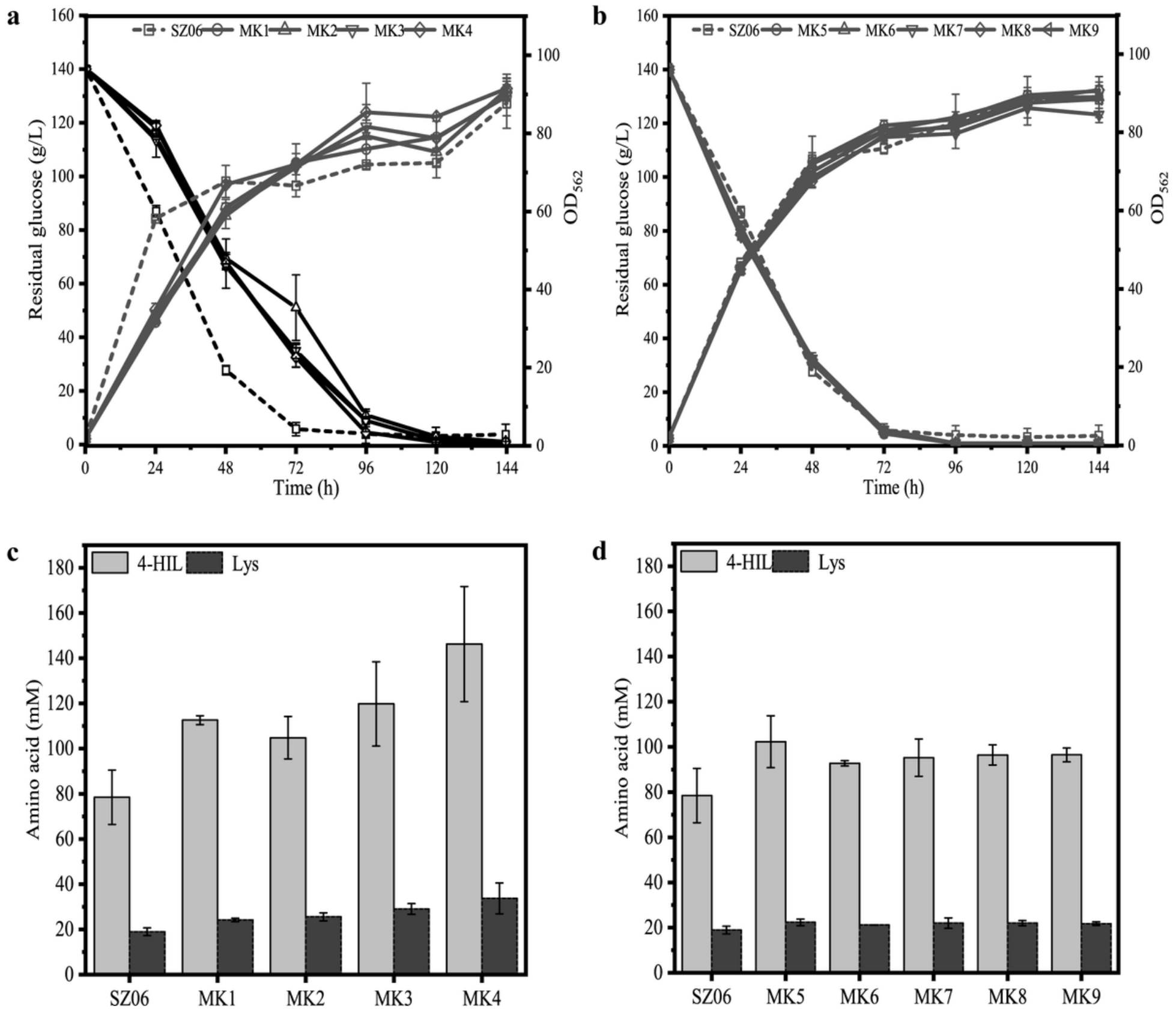

Figure 4

The 4-HIL fermentation of mutant strains MK1-MK9 in shake flasks for $144 \mathrm{~h}$. SZ06 was used as a control strain. a Cell growth and glucose consumption of MK1-MK4, b Cell growth and glucose consumption of MK5-MK9, c 4-HIL and Lys concentration of MK1-MK4, d 4-HIL and Lys concentration of MK5-MK9. 

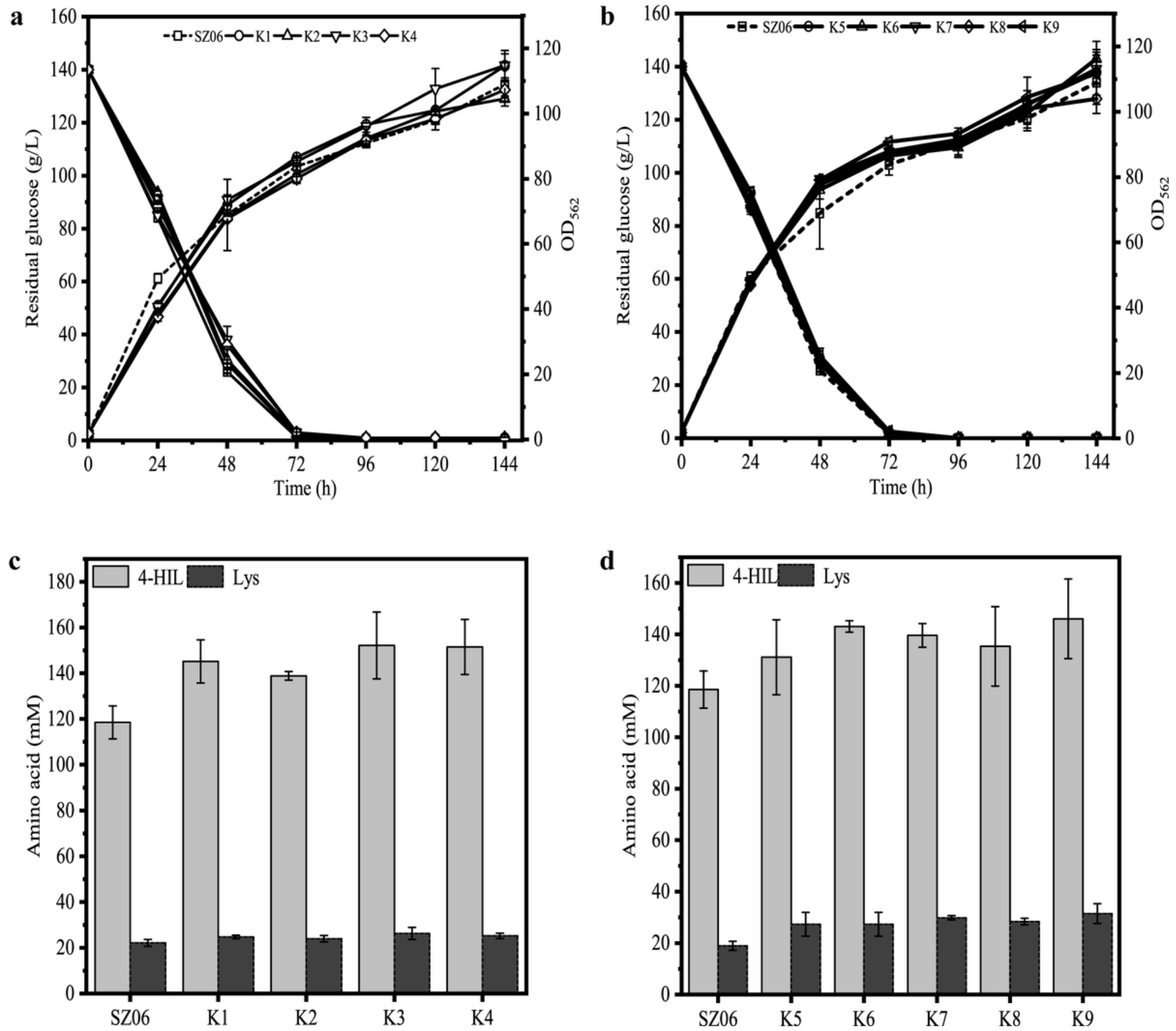

Figure 5

The 4-HIL fermentation of mutant strains K1-K9 in shake flasks for $144 \mathrm{~h}$. SZ06 was used as a control strain. a Cell growth and glucose consumption of $K 1-K 4$, b Cell growth and glucose consumption of $\mathrm{K} 5-\mathrm{K}$, c 4-HIL and Lys concentration of K1-K4, d 4-HIL and Lys concentration of K5-K9. 

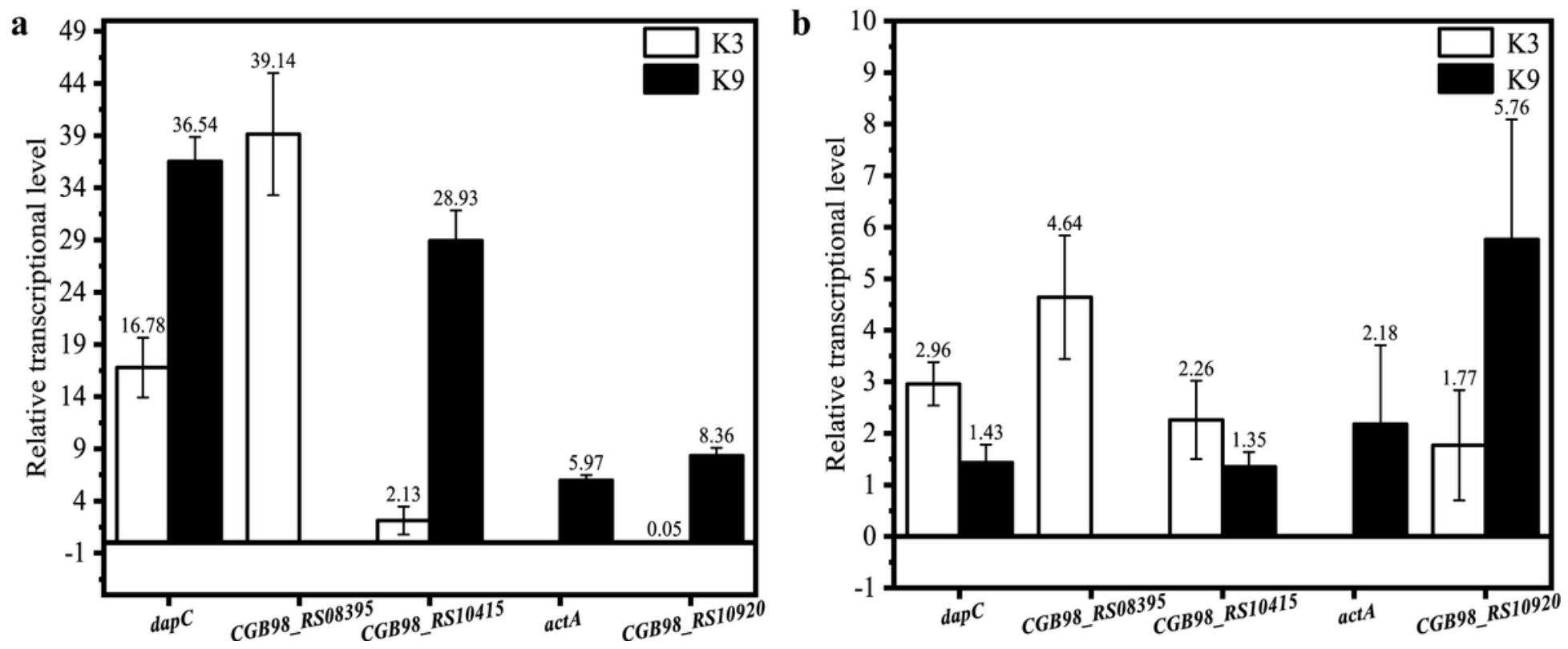

Figure 6

The relative transcription level of related genes in K3 and K9. a The relative transcription level at $24 \mathrm{~h}, \mathrm{~b}$ The relative transcription level at $48 \mathrm{~h}$. The CGB98_RS08395 of K9 and actA of K3 were not mutated and thereby their transcription levels were not detected, 